\title{
Detection of Carbofuran with Immobilized Acetylcholinesterase Based on Carbon Nanotubes-Chitosan Modified Electrode
}

\author{
Shuping Zhang, ${ }^{1,2}$ Shaoyang Li, ${ }^{2}$ Jie Ma, ${ }^{1}$ Fei Xiong, ${ }^{1}$ and Song $\mathrm{Qu}{ }^{1}$ \\ ${ }^{1}$ College of Science, University of Shanghai for Science and Technology, Shanghai 200093, China \\ ${ }^{2}$ College of Environment and Architecture, University of Shanghai for Science and Technology, Shanghai 200093, China
}

Correspondence should be addressed to Shuping Zhang; zhang_lucy9999@yahoo.com.cn

Received 4 January 2013; Accepted 14 February 2013

Academic Editor: Yongfeng Luo

Copyright (C) 2013 Shuping Zhang et al. This is an open access article distributed under the Creative Commons Attribution License, which permits unrestricted use, distribution, and reproduction in any medium, provided the original work is properly cited.

A sensitive and stable enzyme biosensor based on efficient immobilization of acetylcholinesterase (AChE) to MWNTs-modified glassy carbon electrode (GCE) with chitosan (CS) by layer-by-layer (LBL) technique for rapid determination of carbofuran has been devised. According to the inhibitory effect of carbamate pesticide on the enzymatic activity of AChE, we use carbofuran as a model pesticide. The inhibitory effect of carbofuran on the biosensor was proportional to concentration of carbofuran in the range from $10^{-10} \mathrm{~g} / \mathrm{L}$ to $10^{-3} \mathrm{~g} / \mathrm{L}$ with a detection limit of $10^{-12} \mathrm{~g} / \mathrm{L}$. This biosensor is a promising new method for pesticide analysis.

\section{Introduction}

As one group of the most commonly applied pesticides in agriculture, carbamate pesticides, which are typical examples exhibiting fairly high toxicity, have been used more and more extensively. Rapid determination and reliable quantification of trace level of carbamate pesticides are significant to healthiness and environment. The toxic action of carbamate pesticides is due to their ability to irreversibly modify the catalytic serine residue in acetylcholinesterase (AChE), and subsequent inhibition of the AChE effectively prevents nerve transmission by blocking breakdown of the transmitter choline [1]. When AChE was immobilized on the working electrode surface, its interaction with the substrate of acetylthiocholine obtained an electrochemically active product of thiocholine, which can produce an irreversible oxidation peak. The inhibitory effect of carbamate pesticides on AChE was monitored by measuring the decline of oxidation current of thiocholine.

Chitosan (CS) contains large groups of $-\mathrm{NH}_{2}$ and $-\mathrm{OH}$ and has been widely used as a modifying reagent to prepare modified electrode due to its excellent biocompatibility, nontoxicity, cheapness, easy-handling, and high mechanical strength [2]. Its excellent advantages have gained growing interest in using it to immobilize biomolecules in recent years, especially immobilizing enzyme and constructing amperometric biosensors. Their advantages in sensing field include small size with larger surface, particularly the ability to facilitate electron transfer when being used as electrode $[3,4]$; on the other hand, carbon nanotubes (CNTs) are extremely promising for preparation of amperometric biosensors and applications in biochemical sensing field $[5,6]$.

Among the fabrication of biosensor, immobilization of enzyme to solid electrode surface is a crucial step for the design of the biosensor [7]. In our work, CS is used for immobilization of AChE by using LBL technique, leading to a stable AChE biosensor for rapid determination of carbofuran. The presence of CS provides excellent sensitivity and stability of the biosensor and good precision of measurements.

\section{Experimental}

Oxidation of MWNTs and pretreatment of GCE were prepared according to our previous work [8]. Then by dipping into borate buffer solution ( $\mathrm{pH}$ 9.18) for $15 \mathrm{~min}$, the functional groups of MWNTs can be negatively charged. Afterwards, the modified electrode was immersed into $0.5 \%$ CS acetic acid solution (the $\mathrm{pH}$ was adjusted to 5.0 with $\mathrm{NaOH}$ ) and $1 \mathrm{mg} / \mathrm{mL}$ MWNTs solution of $\mathrm{pH} 9.18$ borate buffer solution 


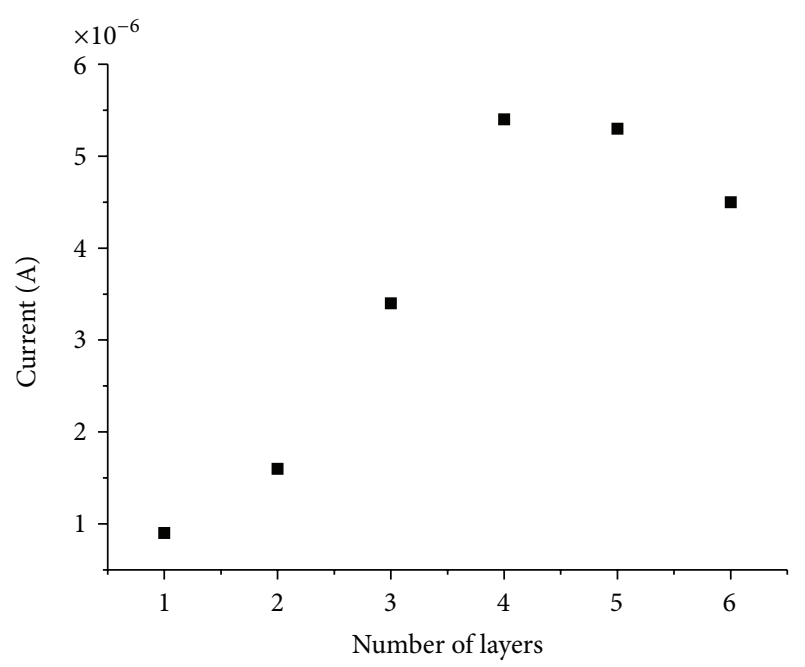

FIGURE 1: Effect of the number of AChE/CS layers ( $n$ ) on the current res-ponse of the biosensor with $0.001 \mathrm{~mol} / \mathrm{L} \mathrm{ATChCl} \mathrm{in} 0.1 \mathrm{~mol} / \mathrm{L}$ $\mathrm{PBS}(\mathrm{pH} 7.40)$ at $0.30 \mathrm{~V}$.

for $15 \mathrm{~min}$ alternately; a five-MWNTs/CS bilayer can be obtained. After preparing MWNTs/CS/ED/GCE, this modified electrode was dipped into $0.5 \%$ CS acetic acid solution (pH 5.0) and AChE solution for 15 min alternately. The modified electrode was carefully washed with double-distilled water after each dipping step. This sequence was repeated until the desired AChE/CS bilayer number was 4 (as shown in Figure 1). In order to get most activity of the enzyme electrode, a AChE membrane was fabricated at the surface. Meanwhile the obtained biosensor of AChE/CS/MWNTs/ $\mathrm{CS} / \mathrm{ED} / \mathrm{GCE}$ was stored at $4^{\circ} \mathrm{C}$ in PBS when not in use.

Cyclic voltammetric and amperometric measurements were performed using an electrochemical analyzer CHI800 connected to a personal computer. A three-electrode configuration was employed consisting of a glassy carbon electrode (GCE) serving as a working electrode, a saturated calomel electrode as a reference electrode, and a platinum wire as an auxiliary electrode. A typical amperometric $i$ - $t$ curve for the biosensor was obtained at $+0.3 \mathrm{~V}$ (versus SCE). On addition of $60 \mu \mathrm{L} 0.1 \mathrm{~mol} / \mathrm{L} \mathrm{ATChCl}$ to $6 \mathrm{~mL}$ PBS with stirring, the oxidation current increased steeply to reach a stable value. The enzyme electrode achieved 95\% of the steady-statecurrent in $10 \mathrm{~s}$. This rapid response was because the MWNTs promoted electron transfer. For the measurement of carbofuran, the obtained AChE/CS/MWNTs/CS/ED/GCE electrode was first immersed in different concentrations of standard carbofuran solution for 10 min (as shown in Figure 2). Then the electrode was transferred to the electrochemical cell of $6.0 \mathrm{~mL}$ pH $7.40 \mathrm{PBS}$ containing $1.0 \times 10^{-3} \mathrm{~mol} / \mathrm{L}$ ATChCl to study the electrochemical response by amperometric $i-t$ curve at $+0.3 \mathrm{~V}$ (versus SCE). The inhibition of pesticide was calculated as follows: Inhibition $(\%)=100 \% \times\left(i_{0}-i_{1}\right) / i_{0}$, where $i_{0}$ was the peak current of ATChCl on AChE/CS/ MWNTs/CS/ED/GCE and $i_{1}$ was the peak current of ATChCl on AChE/CS/MWNTs/ED/GCE with carbofuran inhibition.

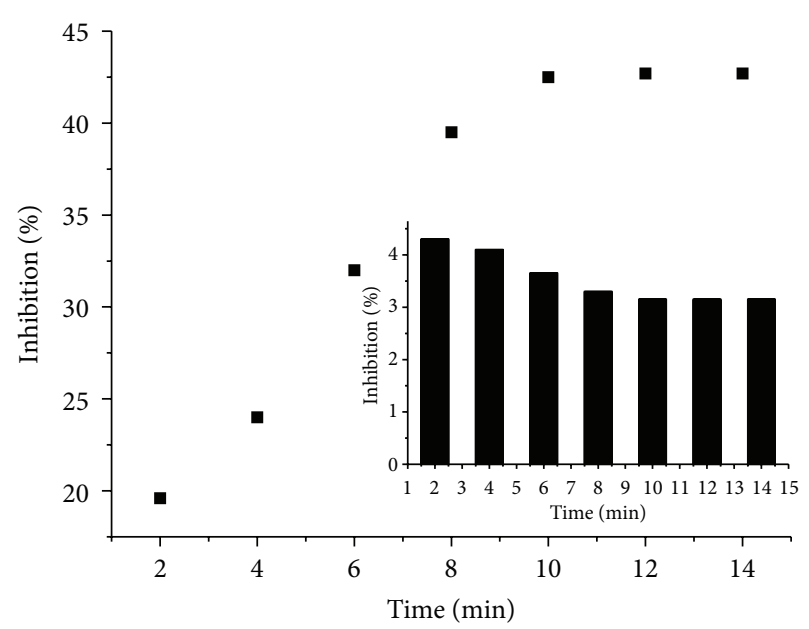

Figure 2: Effect of immersing time in $1.0 \times 10^{-7} \mathrm{~g} / \mathrm{L}$ carbofuran on the inhibition of the biosensor with $0.001 \mathrm{~mol} / \mathrm{L}$ ATChCl in $0.1 \mathrm{~mol} / \mathrm{L} \mathrm{PBS} \mathrm{(pH} \mathrm{7.40)} \mathrm{at} 0.30 \mathrm{~V}$. Inset: effect of immersing time in $1.0 \times 10^{-7} \mathrm{~g} / \mathrm{L}$ carbofuran on the current response of the biosensor with $0.001 \mathrm{~mol} / \mathrm{L} \mathrm{ATChCl}$ in $0.1 \mathrm{~mol} / \mathrm{L} \mathrm{PBS}(\mathrm{pH} 7.40)$ at $0.30 \mathrm{~V}$.

Inhibition (\%) was plotted against the concentrations of the carbofuran to obtain a linear calibration graph.

\section{Results and Discussion}

TCh will be electrochemically oxidized on the surface of GCE under a certain potential; the oxidation process of thiocholine can be described as [9]

$$
\begin{aligned}
& 2\left[\mathrm{H}_{3} \mathrm{C}\right]_{3}-\mathrm{N}^{+}-\mathrm{CH}_{2}-\mathrm{CH}_{2}-\mathrm{SH} \\
& \stackrel{-2 \mathrm{e}}{\longrightarrow}\left[\mathrm{H}_{3} \mathrm{C}\right]_{3}-\mathrm{N}^{+}-\mathrm{CH}_{2}-\mathrm{CH}_{2}-\mathrm{S}-\mathrm{S}-\mathrm{CH}_{2}-\mathrm{CH}_{2}-\mathrm{N}^{+}-\left[\mathrm{CH}_{3}\right]_{3} \\
& \quad+2 \mathrm{H}^{+} .
\end{aligned}
$$

In the current study, the voltammetric characteristics of thiocholine (an enzymatically generated product of acetylthiocholine chloride) on GCE, ED/GCE, and MWNTs/CS/ED/ GCE were investigated by cyclic voltammetry in the potential range of $-0.1 \sim 1.0 \mathrm{~V}$ at a sweep rate of $100 \mathrm{mV} / \mathrm{s}$ in phosphate buffer. Typical cyclic voltammograms are shown in Figure 3. The anodic oxidation peaks were observed on GCE (curve A), ED/GCE (curve B), and MWNTs/CS/ED/GCE (curve C) in $5.0 \times 10^{-3} \mathrm{~mol} / \mathrm{L}$ TCh solution. The anodic peak current of thiocholine on the MWNTs/CS/ED/GCE $\left(I_{\mathrm{pa}}=-61 \mu \mathrm{A}\right)$ is enhanced one time more than that on GCE $\left(I_{\mathrm{pa}}=\right.$ $-29.5 \mu \mathrm{A})$ and also higher than that on ED/GCE $\left(I_{\mathrm{pa}}=\right.$ $-57.5 \mu \mathrm{A})$. Meanwhile, the overvoltage of thiocholine at the MWNTs/CS/ED/GCE $\left(E_{\mathrm{pa}}=0.35 \mathrm{~V}\right)$ is about $250 \mathrm{mV}$ less than that at $\operatorname{GCE}\left(E_{\mathrm{pa}}=0.60 \mathrm{~V}\right)$. The observed low oxidation overvoltage and high anodic oxidation peak of thiocholine at the ED/GCE may attribute to the electrocatalytic activity of MWNTs, which is coming from its edge-plane-like sites at the tube ends [8]. Note that the anodic peak current of thiocholine on the MWNTs/CS/ED/GCE $\left(I_{\mathrm{pa}}=-61 \mu \mathrm{A}\right)$ is 


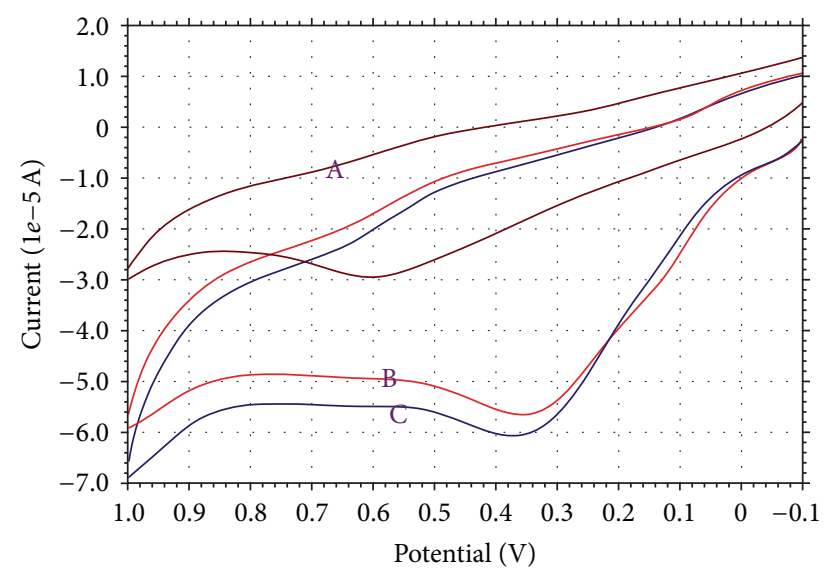

Figure 3: Cyclic voltammograms of GCE (A), DE/GCE (B), and MWNTs/ CS/DE/GCE (C) in $0.005 \mathrm{M}$ thiocholine. Scanning potential range: $-0.1 \sim 1.0 \mathrm{~V}$; potential scanning rate: $100 \mathrm{mV} / \mathrm{s}$.

higher than that on ED/GCE $\left(I_{\mathrm{pa}}=-57.5 \mu \mathrm{A}\right)$. This can be attributed to the electrocatalytic activity of MWNTs adsorbed by CS. It is because there are many free amino groups $\left(-\mathrm{NH}_{2}\right)$ in molecule chains of CS. At low pH (such as acetic acid), free amino groups of CS are protonated and become $-\mathrm{NH}_{3}{ }^{+}$, which can adsorb $-\mathrm{COOH}^{-}$of MWNTs by static gravitation. The processes can be described as

$$
\begin{aligned}
& \text { Protonating process: } \mathrm{CS}-\mathrm{NH}_{2}+\mathrm{H}^{+} \rightarrow \mathrm{CS}^{-} \mathrm{NH}_{3}{ }^{+} \text {. } \\
& \text { Adsorbing process: CS- } \mathrm{NH}_{3}{ }^{+}+\mathrm{COOH}^{-} \rightarrow \\
& \text { CS- } \mathrm{NH}_{3}{ }^{+} \mathrm{COOH}^{-} \text {. }
\end{aligned}
$$

CS has strong adsorptive ability, and it can adsorb the biomolecules stably. In the present paper, $\mathrm{pH}$ of the enzyme solution was kept at 7.40; it was well above the isoelectric point of AChE, which is $\mathrm{pH} 4.50$. The enzyme exists in the form of anion at $\mathrm{pH} 7.40$ [10], facilitating its adsorption with the CS, which makes it suitably incorporated into multilayers, and the multilayers were constructed.

Carbofuran concentrations were detected from their inhibitory effect on AChE. In different concentration solutions of carbofuran, inhibition rate can be determined after the 10 min immersion of enzymatic electrode. Figure 4 is the curves between inhibition rates and pesticide concentration, and it shows a good linearity between inhibition rates and $-\log$ [carbofuran] in the range from $10^{-10} \mathrm{~g} / \mathrm{L}$ to $10^{-3} \mathrm{~g} / \mathrm{L}$ with a detection limit of $1.0 \times 10^{-12} \mathrm{~g} / \mathrm{L}$.

To prove the precision and the practicability of the proposed method, the operational stability and the storage stability of the AChE/CS/MWNTs/CS/ED/GCE electrode were also examined. As shown in Figure 5, when stored at $4^{\circ} \mathrm{C}$ in PBS and measured every day, the AChE/CS/MWNTs/ CS/ED/GCE electrode retained about $80 \%$ of its original sensitivity after 3 weeks. Both the operational stability and the storage stability of the AChE/CS/MWNTs/CS/ED/GCE electrode were much better than those of the AChE/MWNTs/ $\mathrm{CS} / \mathrm{ED} / \mathrm{GCE}$ electrode for five repetitive measurements. The good stability is attributed to the following aspects: the fabrication process is mild, and no damage happened to the

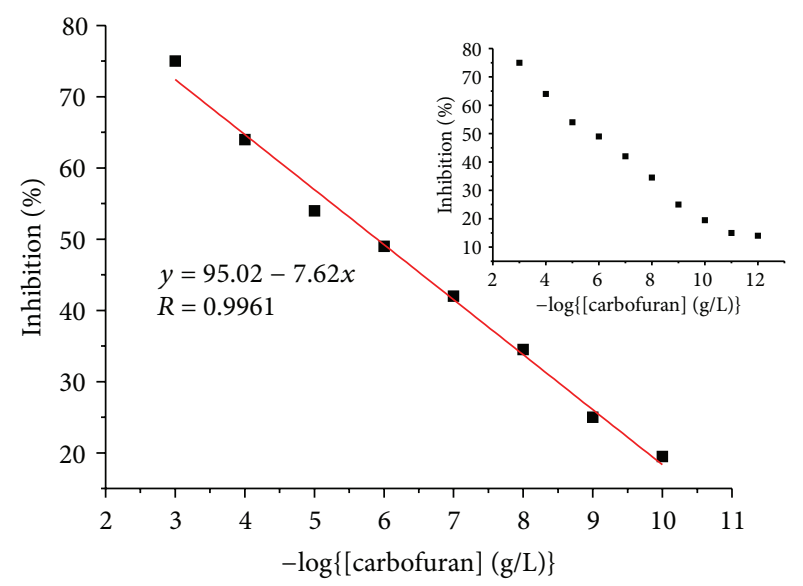

FIGURE 4: Linearity of enzyme inhibition rate and - $\log$ [carbofuran] bet-ween the concentration range of $10^{-10}$ to $10^{-3} \mathrm{~g} / \mathrm{L}$. Insert: detection limit is $10^{-12} \mathrm{~g} / \mathrm{L}$.

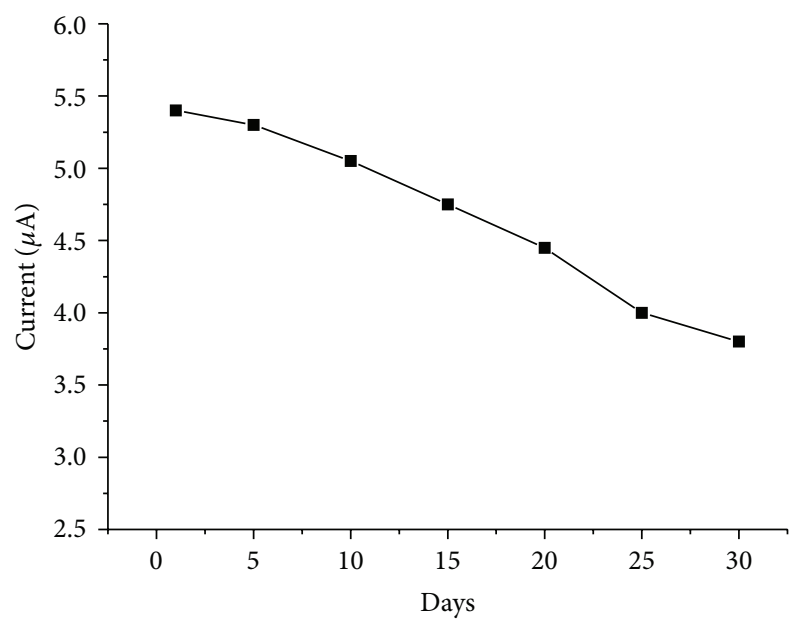

FIGURE 5: The storage stability checked by performing the biosensor in $0.001 \mathrm{~mol} / \mathrm{L}$ ATChCl every day with the biosensor being stored in $0.1 \mathrm{~mol} / \mathrm{L} \mathrm{PBS}(\mathrm{pH} 7.4)$ at $4^{\circ} \mathrm{C}$.

enzyme molecules. On the other hand, the good biocompatibility of CS maintains the biological activity of the enzyme immobilized on the electrode.

\section{Conclusions}

In summary, we are proposing for the first time to use CS for developing enzymatic biosensors based on layer-by-layer technique. We integrate the good biocompatibility of CS and the good conductivity of MWNTs together; meanwhile CS also plays an important role in MWNTs immobilization. The results are promising and indicates that the biosensor possesses higher biological affinity to AChE. So the biosensor proposed has good performance in determination of carbofuran. 


\section{References}

[1] J. Massoulie, L. Pezzementi, S. Bon, E. Krejci, and F. M. Vallette, "Molecular and cellular biology of cholinesterases," Progress in Neurobiology, vol. 41, no. 1, pp. 31-91, 1993.

[2] R. A. A. Muzzarelli and C. Muzzarelli, "Chitosan chemistry: relevance to the biomedical sciences," Advances in Polymer Science, vol. 186, pp. 151-209, 2005.

[3] J. J. Davis, R. J. Coles, H. Allen, and O. Hill, "Protein electrochemistry at carbon nanotube electrodes," Journal of Electroanalytical Chemistry, vol. 440, no. 1-2, pp. 279-282, 1997.

[4] J. Zeng, W. Wei, X. Liu, Y. Wang, and G. Luo, "A simple method to fabricate a Prussian Blue nanoparticles/carbon nanotubes/ poly(1,2-diaminobenzene) based glucose biosensor," Microchim Acta, vol. 160, no. 1-2, pp. 261-267, 2008.

[5] M. L. Pedano and G. A. Rivas, "Adsorption and electrooxidation of nucleic acids at carbon nanotubes paste electrodes," Electrochemistry Communications, vol. 6, no. 1, pp. 10-16, 2004.

[6] F. Valentini, S. Oralanducci, M. L. Terranova, A. Amine, and G. Palleschi, "Carbon nanotubes as electrode materials for the assembling of new electrochemical biosensors," Sensors and Actuators B, vol. 100, no. 1-2, pp. 117-125, 2004.

[7] A. Amine, H. Mohammadi, I. Bourais, and G. Palleschi, "Enzyme inhibition-based biosensors for food safety and environmental monitoring," Biosensors and Bioelectronics, vol. 21, no. 8, pp. 1405-1423, 2006.

[8] S. P. Zhang, L. G. Shan, Z. R. Tian, Y. Zheng, L. Y. Shi, and D. S. Zhang, "Study of enzyme biosensor based on carbon nanotubes modified electrode for detection of pesticides residue," Chinese Chemical Letters, vol. 19, no. 5, pp. 592-594, 2008.

[9] C. E. Banks, T. J. Davies, G. G. Wildgoose, and R. G. Compton, "Electrocatalysis at graphite and carbon nanotube modified electrodes: edge-plane sites and tube ends are the reactive sites," Chemical Communications, no. 7, pp. 829-841, 2005.

[10] P. D. Boyer, H. A. Lordy, and K. Murback, The Enzymes, vol. 7, Academic Press, New York, NY, USA, 2nd edition, 1963. 

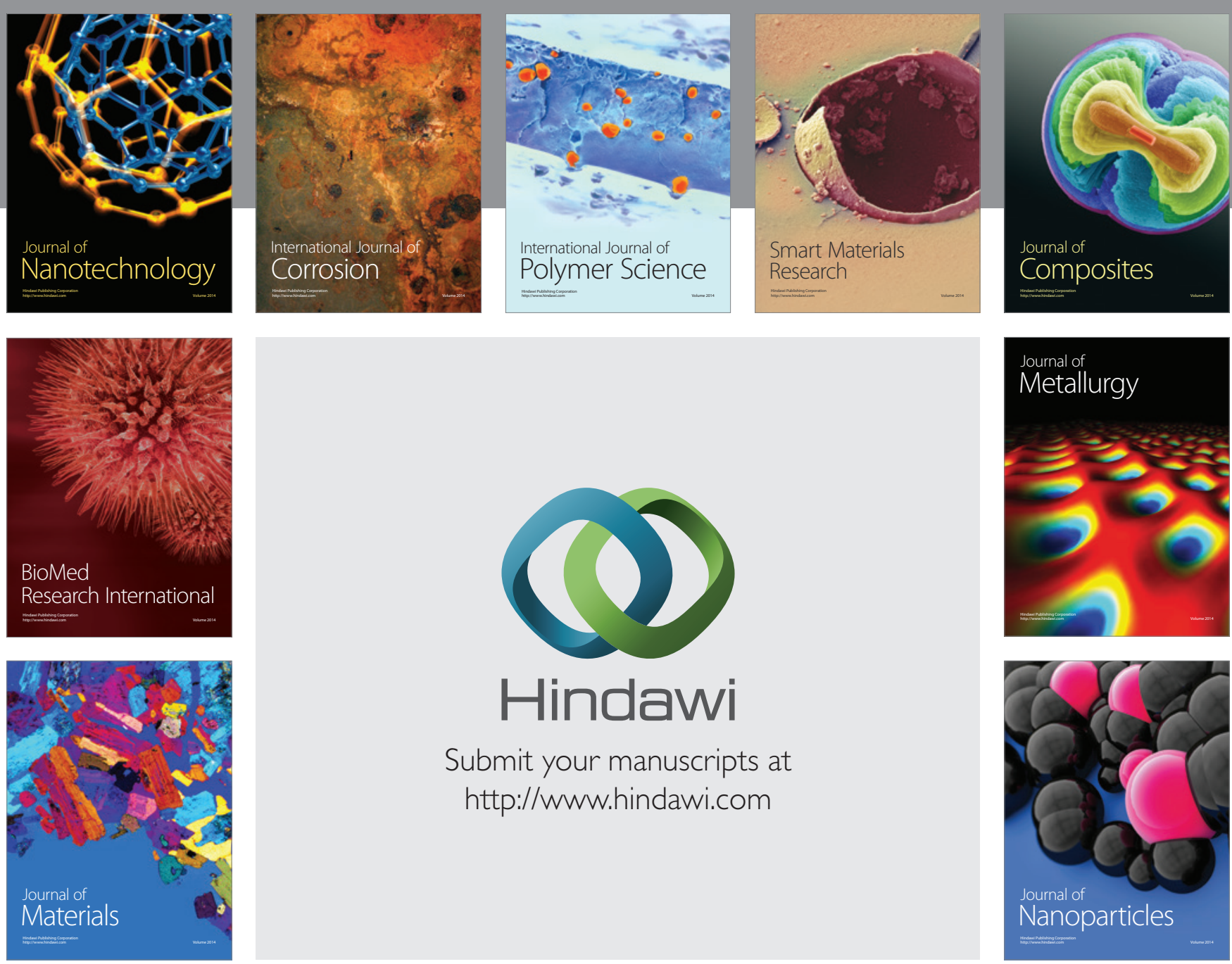

Submit your manuscripts at http://www.hindawi.com
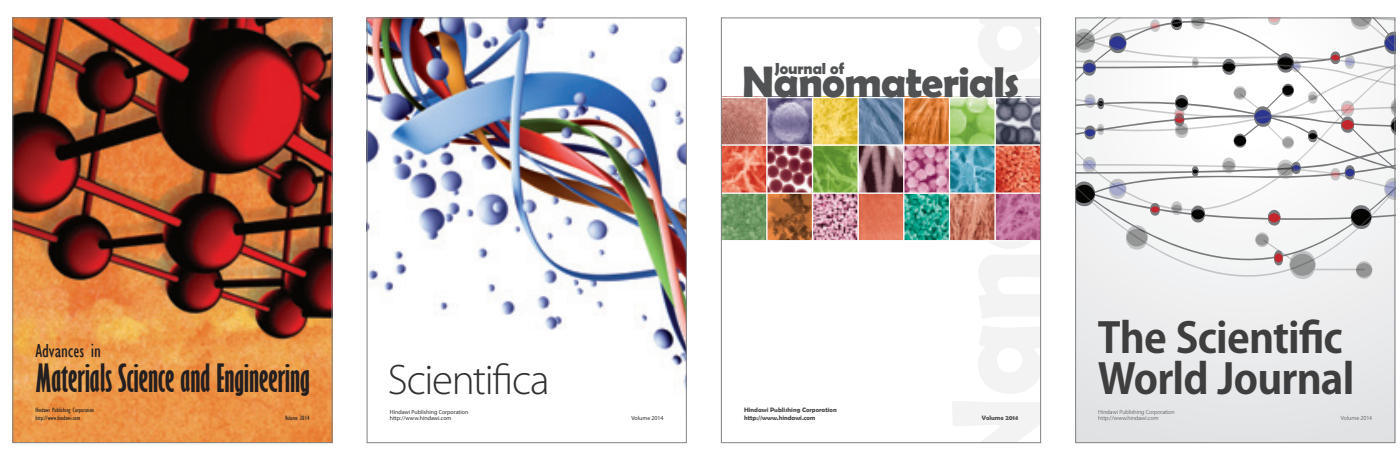

\section{The Scientific World Journal}
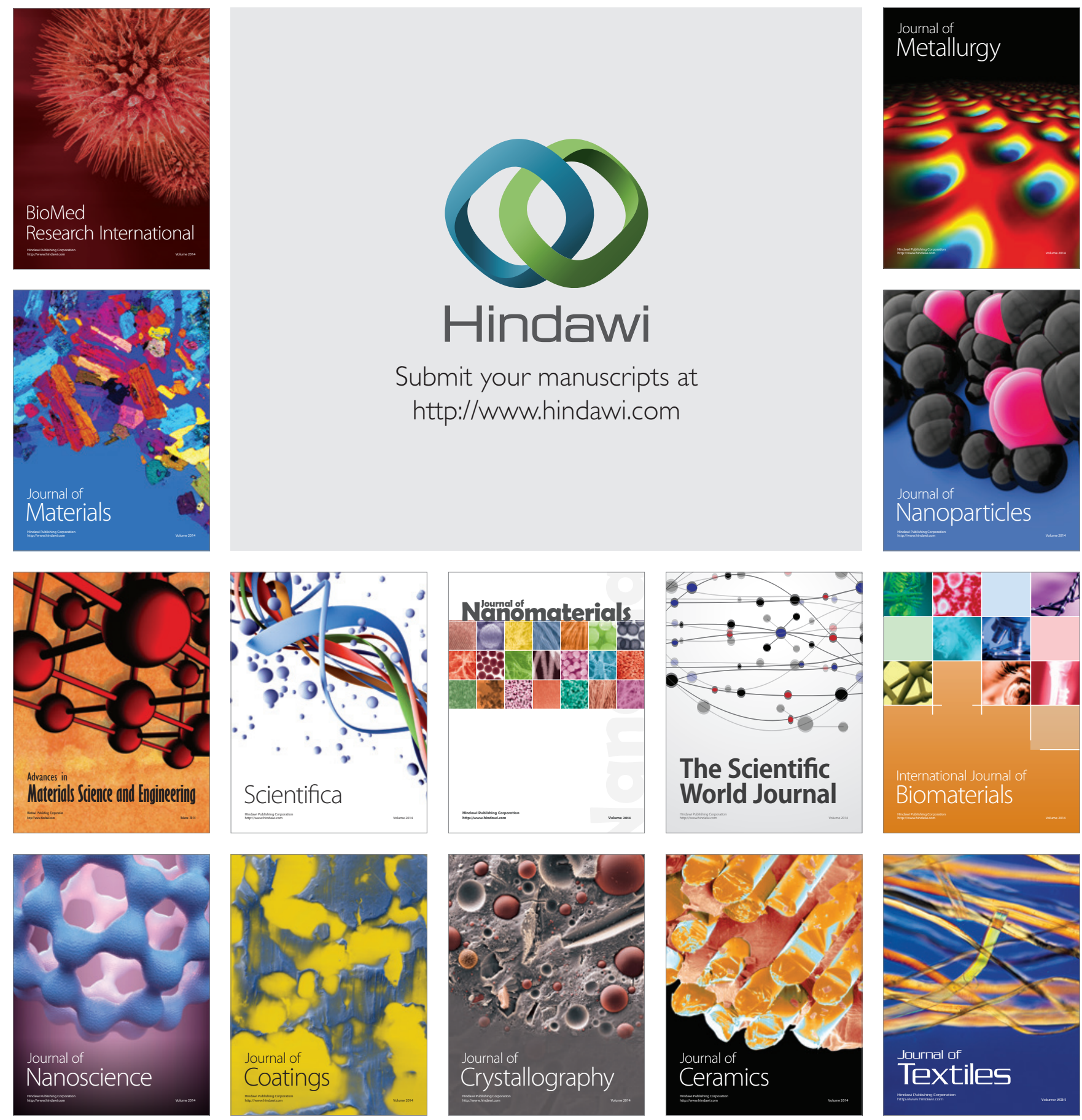